\title{
Derecho Administrativo
}

\section{La indemnización expropiatoria}

\section{POR ÁLVARO BAUTISTA FLORES $(*)$}

\begin{abstract}
Sumario: I. Introducción. La importancia de la indemnización expropiatoria.- II. Naturaleza y requisitos de la indemnización expropiatoria.- III. Rubros incluidos.- IV. Rubros excluidos. La veda al reconocimiento del lucro cesante. Cuestiones acerca de su constitucionalidad.- V. Determinación administrativa y judicial de la indemnización.- VI. Los intereses en la indemnización expropiatoria. Aspectos impositivos. Indexación.- VII. Palabras finales.- VIII. Bibliografía.
\end{abstract}

Resumen: el tratamiento de la indemnización expropiatoria se erige como uno de los principales aspectos a considerar cuando se analiza la expropiación, debido a que, ante el ejercicio de una competencia inalienable que detenta el Estado - ejercida por conducto del órgano Legislativo correspondiente- aquella representa la principal garantía para tutelar el derecho de propiedad de los habitantes, el cual se ve sacrificado en aras del logro del bien común. Por tal motivo, su alcance y extensión aparecen como elementos trascendentales para examinar la legitimidad de las potestades expropiatorias estatales.

Palabras claves: derecho constitucional - derecho administrativo - derecho procesal

\section{Expropriation compensation}

Abstract: the treatment of expropriation compensation stands as one of the main aspects to consider when analyzing expropriation, because, in the face of the exercise of inalienable competence held by the State - exercised through the corresponding Legislative body - that represents erects as the main guarantee to protect the property

$\left({ }^{*}\right)$ Prof. Adscripto a la Cátedra 2 de Derecho Administrativo II, Facultad de Ciencias Jurídicas y Sociales, Universidad Nacional de La Plata (UNLP). 
rights of the inhabitants, which is sacrificed for the sake of achieving the common good. For this reason, its scope and extension appear as transcendental elements to examine the legitimacy of state expropriation powers.

Keywords: constitutional right - administrative law - procedural law

\section{Introducción. La importancia de la indemnización expropiatoria}

La expropiación por causa de utilidad pública se erige como uno de los temas troncales del derecho público. Su correcta utilización ha convertido a este instituto en una herramienta indispensable para promover el bienestar general. No obstante ello, la expropiación como tal, implica el aniquilamiento de uno de los derechos insignias bajo las cuales se cimentó el Estado de Derecho como lo representa el derecho a la propiedad.

En este contexto, como bien lo señalaba el maestro Marienhoff, la expropiación representa un medio ético-jurídico mediante el cual hallan armonía el interés público y el interés privado ante los requerimientos del primero (Marienhoff, 1998), respetando - en todos los casos- los principios elementales de la personalidad humana que representa la finalidad culmine de todo Estado Constitucional de Derecho.

Así las cosas, la propia jurisprudencia de la Corte Suprema de Justicia (en adelante CSJN) destacó que en toda expropiación válida el propósito fundamental que persigue el Estado es el de satisfacer intereses públicos superiores, cuya consolidación exige el sacrificio del dominio particular o privado (Fallos 339: 468). Complementando este aspecto, también en forma constante sostuvo que su fundamento radica en la necesidad de conciliar los intereses públicos con los privados (CSJN, Fallos 268: 112; 326: 2329).

Es en este contexto donde cobra relevancia el tratamiento de la indemnización expropiatoria, debido a que, ante el ejercicio de una competencia inalienable que detenta el Estado - ejercida por conducto del órgano Legislativo correspondiente- aquella representa la garantía para tutelar el derecho de propiedad de los habitantes, el cual se ve sacrificado en aras del logro del bien común.

En el sistema de gobierno monárquico absoluto - es decir en el "Ancien Régi$m e$ " que precedió al constitucionalismo moderno- la expropiación por utilidad pública no tenía un procedimiento especial, ya que para ello eran suficientes las "letras patentes" del rey que las mandaba a ejecutar; y si bien se debía pagar al propietario desposeído una indemnización, se lo hacía irregularmente y con retardos considerables.

La regularidad de la expropiación quedaba librada a la conciencia moral del rey. Cabe mencionar que hasta inclusive los autores de la época que brindaban 
sustento filosófico al absolutismo monárquico (Hobbes o Bodin, por ejemplo) avizoraban un cierto límite con relación a la propiedad de sus súbditos.

Esta facultad discrecional, que originaba abusos, fue uno de los problemas que preocuparon a las asambleas constituyentes de la revolución francesa. La condición de "súbdito" e, inclusive, el otorgamiento de privilegios a ciertos estamentos de la sociedad no garantizaba la protección de sus bienes. Bajo este contexto, la apropiación patrimonial realizada —en muchos casos_ quedaba asimilada a una confiscación, la cual importa una transferencia dominial sin ningún tipo de contraprestación y de manera compulsiva.

El advenimiento del Estado de Derecho, bajo sus ideales liberales, importó un profundo avance en la tutela de la propiedad, que canaliza mediante la satisfacción oportuna de la indemnización cuando el Estado decide hacer uso de la expropiación. Es aquí donde se advierte su importancia, puesto a que una expropiación sin indemnización no es otra cosa que una confiscación, de ahí su antijuridicidad (Marienhoff, 1957). La misma situación se verifica cuando aquella resulta insuficiente o inadecuada.

Vale recordar que se ha justificado a la propiedad como objeto y fin de trabajo del hombre, y como atributo de su personalidad. Ella es anterior a la propia Constitución, coexistente con la sociedad, y, por lo tanto, aquella no hace más que reconocerla, y como el individuo mismo, rodearla de las más firmes garantías (González, 1915).

En el escenario descripto es donde corresponde situarse para tratar el tema en que esta ocasión nos convoca. A raíz de ello, intentaremos poner de manifiesto sus principales aspectos y las cuestiones que han despertado mayores controversias, tanto a nivel doctrinario como en la copiosa jurisprudencia que se registra en la temática. Asimismo, se citarán las disposiciones normativas vigentes, principalmente, del régimen nacional y de la provincia de Buenos Aires.

\section{Naturaleza y requisitos de la indemnización expropiatoria}

La indemnización importa una compensación económica debida por el sacrificio impuesto al expropiado en aras a la utilidad pública (Maiorano, 1978). Representa el resarcimiento de todo lo necesario para que el patrimonio del expropiado quede en la situación que tenía antes (Marienhoff, 1998).

De acuerdo con esta conceptualización se desprenden ciertos rasgos que permiten perfilar su naturaleza, la cual podrá explicar —en alguna medida- los conceptos que se hallan incluidos y excluidos al momento de su conmensuración. 
En primer lugar, superando algunas imprecisiones que provenían del derecho privado (como, por ejemplo, las previsiones del derogado artículo 1324 inciso 1 del Código Civil) la indemnización expropiatoria no puede asimilarse al concepto de "precio", ni siquiera -inclusive- cuando su fijación sea realizada a través del procedimiento de avenimiento. Esta cuestión se explica debido a que, el Estado —en el ejercicio de sus funciones- es quien impone unilateralmente la suma en este concepto, bajo los parámetros establecidos en las respectivas leyes expropiatorias. Esta circunstancia no impide, desde luego, que los sujetos expropiados hagan valer sus derechos al momento de su determinación. Asimismo, las derivaciones del verbo "indemnizar" son las que se consagran en los diversos textos constitucionales (ej.: artículo 17 de la Constitución Nacional; artículo 31 de la Constitución de la provincia de Buenos Aires). La jurisprudencia precisó que “(...) El expropiado no inviste el derecho a la reposición de un bien igual o equivalente al que pierde, pues la suma que paga el expropiador no tiene el carácter de precio y sólo debe satisfacer el resarcimiento por la pérdida del bien y los daños que sean consecuencia directa e inmediata de la expropiación" (Fallos 241: 73).

En conexidad con lo explicado, más allá de que en la actualidad resulte una obviedad, la naturaleza de la indemnización expropiatoria se encuentra regida exclusivamente por disposiciones de derecho público. Al respecto, debemos mencionar que en la expropiación originariamente la competencia jurisdiccional (como ocurre en Francia, donde estas cuestiones son decididas por la justicia ordinaria) y hasta regulatoria estuvo signada por disposiciones de derecho privado.

Esto permitía explicar, por ejemplo, las previsiones que establecía el derogado Código Civil. Luego, con el desarrollo de la ciencia del derecho administrativo, Otto Mayer (1982) se refirió a la existencia de dos etapas o momentos en el marco del juicio expropiatorio (Oyhanarte, 1957), lo cual suponía que la expropiación representaba una institución de carácter mixto. A raíz de esta tesitura, durante un período prolongado se consideró que la discusión y determinación de la indemnización tenía naturaleza de carácter privado. En nuestro país esta tesitura tuvo importantes consecuencias prácticas, atento a que los procesos expropiatorios enderezados a discutir los términos de la indemnización quedaron englobados dentro de los alcances del concepto de "causa civil". Esto permite comprender importante cantidad de sentencias que registró la CSJN en estas cuestiones, en las cuales - en muchos supuestosel máximo tribunal emitía sus sentencias aplicando las legislaciones locales.

Esta postura comenzó tibiamente a ponerse en crisis (Ej.: en Fallos 212: 600 ya se mencionó que la naturaleza del juicio expropiatoria era definitivamente de derecho público), y a partir del año 1957 fue dejada de lado por la jurisprudencia de la CSJN. En Fallos 238: 335 categóricamente se estableció que: “(...) La expropiación, como institución de derecho público, está regida por principios propios y no por los de la compraventa, figura jurídica exclusiva del derecho privado (...) 
la expropiación es un acto unilateral, acto de poder de la autoridad expropiante, por el cual ésta adquiere la propiedad del bien declarado de utilidad pública sin el concurso de la voluntad del expropiado y sin otro presupuesto legal que el pago de la indemnización debida por el desapropio. Esta indemnización sólo comprende el valor objetivo del bien y los daños y perjuicios que sean una consecuencia directa e inmediata de la expropiación".

A partir de estas condiciones, pueden comenzar a perfilarse las características y recaudos de la indemnización expropiatoria. Si nos guiáramos exclusivamente por la mayoría de los textos constitucionales ( $\nu$ gr. nación y provincia de Buenos Aires), el único recaudo que se establece es la necesidad de que la indemnización sea "previa". Sin embargo, como veremos seguidamente, son inherentes a su naturaleza otras características de sumo valor para comprender el modo en que es conmensurada la indemnización.

Sobre este punto, no existe controversia alguna en considerar que la indemnización expropiatoria deberá ser "justa", e inclusive, es el criterio vigente en la jurisprudencia de la CSJN (Conf. Fallos 326: 2329). Al respecto, cabe señalar que dicho recaudo fluye implícito de la Constitución, atento a que los constituyentes, al utilizar la palabra indemnización sin limitarla en su contenido, asentaron un concepto amplio que envuelve a todos los perjuicios y daños, dando a la contraprestación del expropiante una calidad verdaderamente justa (Villegas, 1973).

El carácter examinado trae aparejadas las siguientes consecuencias. En este sentido, la Corte ha sido categórica al entender que "(...) El principio de "justa" indemnización, basado en la garantía de la propiedad (artículo 17 de la Constitución Nacional) exige que se restituya íntegramente al propietario el mismo valor de que se lo priva, ofreciéndole el equivalente económico que le permita, de ser posible, adquirir otro bien de similares características" (Fallos 326: 2329; 317: 377). Asimismo, un temperamento similar fue también sostenido en Fallos 305: 407; 305: 1897; 302: 1406; 300: 762; 298: 463; 298: 550; 296: 546; 296: 55; 281: 354; 268: 112. Por ello, la indemnización no podrá erigirse como una fuente de pérdidas o de ganancia para el expropiado (Fallos 305: 1897).

La representación del concepto de "justa indemnización" aparecería regulado mediante la locución "valor objetivo", la cual será abordada en el próximo punto.

Como no puede ser de otra forma, el artículo 28 de la Constitución Nacional constituye otro factor para tener en consideración para determinar la justicia de la indemnización. Si aquello no ocurre, estaremos en presencia de un accionar irrazonable, lo cual es vedado por el propio texto constitucional.

Continuando con el abordaje de esta característica, en la actualidad se presenta un aspecto singular que merece su tratamiento. La jerarquía supralegal o 
constitucional de ciertos tratados internacionales (conf. artículo 75 inc. 22 de la Constitución Nacional) podría brindar nuevos fundamentos a la hora de reforzar el concepto de indemnización "justa". De hecho, el derecho de propiedad ha sido alcanzado y protegido por los diversos instrumentos (conf. artículo XXIII de la Declaración Americana de los Derechos y Deberes del Hombre; artículo 17 de la Declaración Universal de Derechos Humanos; artículo 21 de la Convención Americana de Derechos Humanos - $\mathrm{CADH}-$ ).

Respecto de este último Tratado, el cual posee una amplia aplicación en nuestra jurisprudencia en virtud de la propagación del control de convencionalidad, se genera una situación especial. Así las cosas, el artículo 75 inc. 22 antes citado expresa que la jerarquía que le otorga la Constitución a los Tratados es en "las condiciones de su vigencia". En este entendimiento, la ley № 23.054 - por la cual ingresa al ordenamiento nacional la $\mathrm{CADH}$ - contempló la reserva realizada en su momento por la República Argentina, por la cual no quedarán sujetas a revisión de un tribunal internacional cuestiones inherentes a la política económica del Gobierno, ni tampoco se considerará revisable lo que los tribunales nacionales determinen como causas de utilidad pública e interés social, ni lo que estos entiendan por indemnización justa (PTN, Dictámenes 238: 87). Por tal motivo, a priori, no podría invocarse a la Convención y a su jurisprudencia para fundamentar el punto bajo análisis, o, por ejemplo, para cuestionar los rubros excluidos de reconocimiento en la indemnización.

La condición de justa permite caracterizar a la indemnización expropiatoria como una "deuda de valor". En este sentido, como bien lo puntualizó Marienhoff (1998), no representa una deuda de cantidad o pecuniaria. Conteste a ello, la doctrina judicial ha sostenido que "(...) la indemnización otorgada al expropiado constituye en los términos como lo han legislado los artículos 17 de la Constitución Nacional, 10 de la ley 21.499 y 2511 del Código Civil una de las denominadas deudas de valor, en las que el dinero representa solamente la medida del objeto de la prestación, el cual consiste en una determinada utilidad que el deudor debe procurar al acreedor (...)" (Fallos 307: 2006). En un sentido análogo, posteriormente se expresó que "(...) la indemnización en materia expropiatoria debe entenderse como el resarcimiento de todo lo necesario para que el patrimonio del expropiado quede en la situación que tenía antes de la expropiación, la que traduce un cambio de valores: el expropiado deja de ser propietario de la cosa o bien objeto de la expropiación y se convierte en titular de una suma de dinero" (Fallos 329: 5467; 337: 70).

Este precepto, el cual se encuentra íntimamente relacionado con el "valor objetivo", permite tener en consideración la cuantía del bien a expropiar. En efecto, al ser una deuda de valor, su carácter se mantendrá hasta que se realice el pago total de la indemnización, lo cual permite una determinación ulterior acerca de su monto. Es aquí donde radica el fundamento por el cual se abona el monto "actual" de los bienes que resultan ser abarcados por la expropiación. 
A raíz de ello, en su momento, le confirió basamento a la posibilidad de prever mecanismos indexatorios, como, por ejemplo, se establecen en el artículo 20 del decreto-ley No 21.499.

Los aspectos a incluirse en concepto de indemnización deberán ser sufragados en dinero en efectivo, salvo conformidad del expropiado (artículo 12 decretoley 21499; artículo 8 ley 5708; Fallos 271: 402). Si bien se trata de una deuda de valor, al no ser posible reponer un estado de cosas, no cabe sino la indemnización en dinero (Casas y Romero Villanueva, 2014). Con sustento en este requisito, se ha descartado la aplicación del régimen de consolidación de deudas en materia de expropiaciones, declarando -inclusive - la inconstitucionalidad de las normas que establecían dicha posibilidad (Fallos 318: 445).

El único recaudo de raigambre constitucional expreso es el atinente a que la indemnización deberá ser "previa". Esta condición se explica o entiende en función del contexto histórico que rodeó al nacimiento de la figura de la expropiación, debido a que, en los casos de ejercitarse dicha atribución, el modo en el cual los habitantes veían - en cierto modo- garantizado su derecho de propiedad, quedaba extinguido por la utilización de dicha herramienta.

El carácter "previo" indica que el monto que compone la indemnización deberá ser integrado con antelación a que opere la transferencia efectiva del bien o lo bienes expropiados. Por imperio de esta calidad, salvo escenarios de emergencia o urgencia, al instarse cualquier expropiación deberán contarse con los fondos necesarios para afrontar los costos de la indemnización. En efecto, una antigua jurisprudencia de la CSJN ya disponía que “(...) el Congreso debe, al ordenar la expropiación de bienes, determinar los recursos con los cuales deberá pagarse la indemnización respectiva" (Fallos 186: 151).

Sin embargo, este requisito - en la práctica - pareciera encontrarse relativizado. En este sentido, teniendo en consideración los motivos que subyacen en la declaración de la utilidad pública, la transferencia del bien expropiado puede tener lugar con antelación a la fijación definitiva de la indemnización. De hecho, la conmensuración de los rubros puede transitar por diversas instancias judiciales, lo cual - como se sabe-insume un tiempo considerable en nuestro país.

En consecuencia, desde antaño, se ha postulado una interpretación amplia del alcance de la indemnización previa (Bielsa y Luqui, 2017). De esta manera, no sorprende la postura de la CSJN, al considerar que

(...) si bien el artículo 17 de la Constitución consigna en términos absolutos que la indemnización debe ser previa, el Congreso puede, consultando la razón y propósitos de ese precepto, conciliarlo con las 
exigencias de progreso y bienestar público, emergente de la propia ley fundamental (artículos 14 y 28 Constitución Nacional). (...) La doctrina y la legislación han decidido, en cuanto al requisito de la indemnización previa, que no es posible sujetarlo a la interpretación rigurosa y literal (Fallos 108: 240).

Por tal circunstancia, fundamentalmente teniendo en consideración las necesidades de los sujetos expropiantes, el precepto de la indemnización previa queda provisoriamente satisfecho mediante la consignación judicial del monto establecido (conf. artículos 22 y 25 del decreto-ley No 21.499) vía administrativa. Esta situación también suele darse, por ejemplo, en los supuestos en los cuales se ignoren los propietarios o los mismos no puedan ser fehacientemente notificados.

En estos casos, cuando es promovida la demanda de expropiación directa se solicitará al juez interviniente la apertura de la cuenta bancaria correspondiente, para depositar la suma a consignar. Cabe aclarar que el sujeto expropiado, sin la necesidad de consentir aquella suma, podrá retirar y tomar a cuenta de lo que al final se estipule (conf. artículo 23 del decreto-ley No 21.499).

Finalmente, en función de la intensidad que posee la expropiación —por representar un supuesto de extinción del derecho real de dominio- el criterio hermenéutico rector en materia indemnizatoria postula que la misma - en caso de duda - debe estar a favor del expropiado. Así lo explica la jurisprudencia añeja de la Corte, cuando consagra que "(...) toda expropiación, a la vez que sea necesaria para el bien público, es odiosa. Tanto en materia de avalúos como de perjuicios en las cosas expropiadas, en caso de duda debe siempre estarse en favor del expropiado" (Fallos 15: 254). En sintonía con este criterio, también se sostuvo en Fallos 195: 187 en donde se expresó que, para no lesionar el patrimonio del propietario, en caso de duda, la indemnización debe ser examinada a favor del expropiado.

\section{Rubros incluidos}

La determinación de la indemnización expropiatoria, a fin de satisfacer los postulados que analizamos anteriormente, se construye en torno a la idea del denominado "valor objetivo del bien" (conf. artículo 10 del decreto-ley) o el "justo valor de la cosa o bien" (artículo 8 ley 5708). A este tópico, se les añadirán los daños y perjuicios directos que genere la indemnización y a los intereses.

Para algunos, en sintonía con las exclusiones que ya se verán, este postulado reposa en la noción de la justicia distributiva que es la que rige en materia expropiatoria (González Arzac, 1975). Asimismo, lo "objetivo" se asocia con un valor intersubjetivo, comunitario o social de un bien (Linares, 1997). 
Según la opinión de la Corte, el valor objetivo es lo que la cosa realmente vale para la generalidad en el mercado de los bienes de esa especie, correspondiente al lugar expropiado y al tiempo de la desposesión (Fallos 217: 804). Con mayor precisión, en otro precedente, sentó que el valor objetivo debe ser entendido como el valor a plaza y al contado, ajustado a las cualidades intrínsecas de la cosa, teniendo en consideración las circunstancias de lugar y tiempo (Fallos 237: 38).

En este contexto, comienza a avizorarse lo que constituye uno de los aspectos más controvertidos de la indemnización expropiatoria. La doctrina autoral postula que otra de las condiciones de la indemnización es que la misma sea "integral" (Marienhoff, 1998) (Bielsa y Luqui, 2017) (Maiorano, 1978). Sin embargo, por las limitaciones que se prevén en los distintos ordenamientos legales, esta integralidad dista de asimilarse al criterio de reparación plena, propio - por ejemplo- de los supuestos de responsabilidad estatal ilícita. Aunque, de todas maneras, fruto de su naturaleza estrictamente pública, el valor objetivo no se asimila estrictamente a la idea civilista del daño emergente (Cassagne, 2002).

Bajo estos términos, debe entenderse por indemnización integral —en materia expropiatoria - a la que se ajusta a las previsiones legales (Fallos 241: 73). Por añadidura, la expropiación no ha de ser fuente de pérdidas, pero tampoco de ganancias para el expropiado y que la indemnización ha de atender a las concretas circunstancias del caso y no a situaciones hipotéticas o eventuales (Fallos 305: 1897).

En suma, la indemnización por expropiación debe ser siempre equitativa (Fallos 7: 51; 32: 358; 181:250).

La normativa vigente y la casuística nos indican que los conceptos que conforman la indemnización expropiatoria son los siguientes:

a) Los daños que sean consecuencia directa e inmediata de la expropiación (artículo 10 decreto-ley 21.499): estos perjuicios deberán ser analizados a la luz de las reglas en materia de responsabilidad, fundamentalmente, en función de las cuestiones de hecho que sirvan de sustento al caso y al nexo de causalidad que se invoque.

b) Los gastos de mudanza (Fallos 204: 205).

c) Las indemnizaciones abonadas por el despido de empleados (Fallos 258: 213; 270: 210).

d) La pérdida de la aptitud funcional de la actividad realizada en el inmueble (Fallos 311: 548; en este caso la expropiación efectuada había producido una restricción en la práctica de la actividad de tiro que efectuada el expropiado). 
e) Las mejoras necesarias o impostergables con posterioridad a la afectación del bien a utilidad pública (artículo 11 decreto-ley 21499; artículo 13 ley 5708; Fallos 240: 219; 221: 519).

f) El traslado de hacienda y bienes (Fallos 301: 1205).

g) La interrupción de contratos.

h) Gastos en honorarios profesionales (Fallos 239: 123), comisión de martilleros; gastos de escrituración.

i) El valor panorámico e histórico, en cuanto sean debidamente comprobados, también podrán integrar el valor objetivo del bien a expropiar (artículo 8 in fine, ley 5708). El régimen nacional guarda silencio, pero, al derogarse la prohibición respecto a esta cuestión que se traía de la legislación anterior - 13264- se considera que dicho rubro se encuentra incluido.

Es interesante resaltar las particularidades que se han planteado al momento de determinar el quantum indemnizatorio en las expropiaciones de empresas concesionarias de servicios públicos (Oyhanarte, 1957).

En tal sentido, vale recordar que el artículo 40 de la derogada Constitución de 1949 había establecido una fórmula específica para estos supuestos, la cual había sido iterada en el artículo 16 de la ley 5708 (posteriormente declarado inaplicable por la jurisprudencia de la SCBA, Ac. y Sen. T. II 1961). Sucintamente, podemos destacar que en estos casos la indemnización se extenderá al valor de los bienes afectados al servicio (Fallos 141: 190; 201:432; 204: 626), y al lapso que falte para la culminación del contrato de concesión, que representa el resarcimiento del valor del contrato original. Dicho criterio fue reconocido por la jurisprudencia de la CSJN en Fallos 230: 280; 254: 441.

Otro punto álgido en esta cuestión, ha sido si correspondía el reconocimiento del costo histórico u original, o más bien, el costo de reproducción. Mediante este rubro se permite compensar el valor no amortizado de la inversión realizada. Vale mencionar que este aspecto no ha sido desconocido en nuestro país, atento a que, este criterio fue oportunamente sentado en Fallos 212: 2; 176: 363; 224: 706. Entendemos que, en caso de adoptarse el criterio relativo al "costo histórico" —el cual únicamente englobaría al esfuerzo patrimonial inicial-conduciría a situaciones injustas, lo cual se traduciría en una indemnización irrazonable.

Finalmente, debe señalarse que a nivel internacional (v.gr:: los casos sometidos a la jurisdicción del CIADI en cuestiones de inversiones extranjeras), el criterio aplicado en estos casos - generalmente a partir de nacionalizaciones- se 
establece en función a la utilidad actual que represente el servicio, compensando el valor producido - neto de descuentos- con el precio abonado por la concesión (Aguilar Valdez, 2006) (Ymaz Videla, 1999).

Una cuestión aún controvertida en esta materia es la atinente al reconocimiento de los rubros "valor llave" y "empresa en marcha".

El "valor llave" se emparenta con la realidad económica vinculada a la capacidad y seguridad productiva del negocio, lo cual puede traducirse en la posibilidad futura de rendimiento en mérito a la clientela, a la firma reconocida, a la fama, al crédito, a las marcas de la fábrica, etcétera.

La regla general en la jurisprudencia de la Corte indica que este rubro no ha sido reconocido (conf. Fallos 225: 451; 254: 441; 300: 299; 303: 692; 303: 1011; 312: 1725; 319: 2108). No obstante ello, corresponde indicar que en forma aislada, dicho rubro ha encontrado reconocimiento (Fallos 245: 252; 312: 2444).

Sin embargo, pareciera advertirse un sutil cambio en la posición de la CSJN. Entendemos que esto es así debido a que, pareciera haber dejado de lado el criterio absolutamente restrictivo en la materia. En este punto, en la sentencia recaída en Fallos 316: 1756 se entendió que "(...) no corresponde admitir el resarcimiento del valor llave en materia de expropiación". Posteriormente, la Corte indicó que “(...) salvo supuestos excepcionales, no corresponde reconocer el valor llave en materia expropiatoria" (Fallos 319: 2108), con lo cual —más allá de su carácter excepcional- cabría la posibilidad de admitir este rubro.

Una suerte similar pareciera correr el valor "empresa en marcha", el cual se asimila al resultado de los negocios hasta el momento donde tiene lugar la expropiación. Aquí las soluciones han sido más dispares en cuanto a su reconocimiento. Por ejemplo, en la sentencia registrada en Fallos 176: 363 - a fin de dar sustento a la viabilidad de este rubro- la Corte expresó que un bien vale, principalmente, por lo que produce o es capaz de producir en épocas normales (Bidart Campos, 2008). Es decir, si la utilidad pública declarada tuvo en consideración el rendimiento - por ejemplo - de una empresa o emprendimiento a expropiar no existiría para dar cauce a su procedencia (Fallos 208: 143; 209: 333).

De acuerdo con ello, debe destacarse que en el precedente registrado en Fallos 300: 299 el máximo tribunal descartó la chance de su reconocimiento debido a que la empresa expropiada no había aportado ninguna prueba y que aquella — por su estado financiero- contaba con pocas posibilidades de mantener su actividad en el tiempo. Asimismo, en Fallos 312: 1725 tampoco se hizo lugar a esta pretensión, atento a que la precaria coyuntura de la empresa conspiraba con las posibilidades de sostener su giro económico. En resumen, como bien lo ha planteado Perrino 
(2009), en los fallos mencionados se desestimó la reparación del ítem empresa en marcha debido a las pocas posibilidades de las empresas expropiadas de continuar con el desarrollo de su actividad empresarial.

Por tal motivo, este rubro usualmente no ha sido reconocido cuando se ha procedido a expropiar empresas concursadas o en procesos de quiebra.

\section{Rubros excluidos. La veda al reconocimiento del lucro cesante. Cuestiones acerca de su constitucionalidad}

El fundamento que posee la utilización de la figura de la expropiación, por hallarse en juego el bien común, acarrea la necesidad de un esfuerzo compartido entre la sociedad (quien contribuye al sostenimiento económico del Estado) con el particular que realiza el sacrificio especial, consistente en la extinción de su derecho real de dominio.

Estas ideas son las que cuajan al momento de establecer limitaciones en cuanto al reconocimiento de ciertos rubros en la indemnización expropiatoria. La penetración de los postulados de la justicia distributiva, la noción que veda el enriquecimiento injustificado (tanto del Estado como del particular) ha llevado, desde antaño, a prever exclusiones específicas cuando se conmensura una indemnización a causa de una expropiación.

Por tal motivo, la indemnización expropiatoria asume el carácter de tarifada, conforme a los rubros que se encuentran vedados para su determinación.

De conformidad a lo expuesto, la normativa ha establecido los siguientes valores excluidos:

a) No se considerarán para su cómputo las circunstancias de carácter personal (artículo 10 del decreto-ley No 21.499).

b) No se considerarán valores afectivos (artículo 10 del decreto-ley № 21.499; guarda silencio en este punto la ley provincial 5708).

c) No se reconocen las ganancias hipotéticas (artículo 10 del decreto-ley No 21.499). Estas son aquellas que revisten la calidad de eventuales, cuya realización es de carácter incierto. Al respecto, la jurisprudencia ha entendido que "(...) los gastos de publicidad por la puesta en marcha de un casino, que se efectúan para procurar ganancias futuras o hipotéticas, no pueden ser considerados como daños que sean consecuencia directa e inmediata de la expropiación" (conf. Fallos 281: 360). También se incluyen dentro de esta prohibición a los intereses de la deuda hipotecaria, por el 
saldo del precio contraída por el dueño del bien expropiado y a la explotación futura de una cantera de granulado pómez por la expropiada (Fallos 217: 804). Asimismo, quedó englobado dentro del concepto "ganancias hipotéticas" a la posibilidad de realizar la subdivisión de un block de más de cien hectáreas (Fallos 211: 1641).

d) El mayor valor que pueda conferir al bien la obra a ejecutarse (artículo 10 decreto-ley 21.499; artículos 9 y 11 ley 5708), tampoco deberá quedar incluido en la indemnización (Fallos 159: 351).

e) Tampoco serán consideradas las mejoras realizadas en el bien - a excepción de las necesarias- (artículo 11 decreto-ley 21.499; artículo 13 ley 5708).

f) Los contratos celebrados con posterioridad a la declaración de utilidad pública (Fallos 217:804) no podrán computarse a los efectos de la indemnización.

El lucro cesante entendido como aquellas ventajas económicas esperadas de acuerdo con probabilidades objetivas estrictamente comprobadas (Fallos 306: 1409; 316: 1025). Este rubro conforma los parámetros de las indemnizaciones plenas o integrales, siempre y cuando - claro está— resulte debidamente acreditado por quienes lo invocan.

Pareciera que la propia esencia que posee la indemnización expropiatoria, en razón de las finalidades que persigue la figura de la expropiación haría razonable esta limitación. Este es el criterio sostenido, por ejemplo, por el profesor Marienhoff (1998).

Así las cosas, desde sus orígenes, los diversos regímenes expropiatorios han consagrado la veda al reconocimiento del lucro cesante (artículo 10 in fine decreto-ley 21499; artículo 8 ley 5708). Como ya se sostenía en el derecho alemán, existe una "convicción jurídica general" limitatoria de la indemnización (Forsthoff, 1957).

Quizá por esta concepción tan arraigada, los regímenes expropiatorios -en lo que concierne a este punto- siempre superaron el test de constitucionalidad. Esto fue establecido, por ejemplo, en las sentencias registradas en Fallos 217: 617; 312: 2224; 317: 617 .

Ahora bien, no obstante los fundamentos que se registran para sustentar la prohibición del lucro cesante (principios de justicia distributiva, intereses generales, sacrificio especial, etcétera), corresponde mencionar - a nuestro juicio-que 
dicha veda podría conllevar a situaciones injustas o razonables. Es por ello que los problemas que podrían darse con la imposibilidad de reconocer el lucro cesante o las ganancias hipotéticas pueden ser sorteados con una interpretación razonable del concepto de "valor objetivo". Sin perjuicio de las vicisitudes anteriormente descriptas, los derechos emergentes de los contratos en curso (hasta su finalización), el valor llave o el valor empresa en marcha podrán ser incluidos en este concepto, sin que resulten englobados en la veda al lucro cesante.

Lo expuesto no implica un reconocimiento automático de los rubros que puedan conformar el valor objetivo, atento a que estas cuestiones estarán sometidas a estrictas exigencias probatorias.

\section{Determinación administrativa y judicial de la indemnización}

La determinación de la indemnización en el ámbito nacional está sujeta a la intervención obligatoria del Tribunal Nacional de Tasaciones de la Nación, conforme se desprende de los artículos 13 y 15 decreto-ley 21.499.

En el seno de sus atribuciones legales, establecidas en el decreto-ley № 21.626, el Tribunal de Tasaciones ha emitido diversas normas que otorgan pautas concretas para la conmensuración de los diversos rubros que compondrán la indemnización expropiatoria.

A mayor abundamiento, las normas más relevantes son las siguientes:

Norma TTN 1.6 Principios y Conceptos de Valor - 17 de noviembre de 2014;

Norma TTN 2.3 Definiciones Técnicas y Legales - 6 de marzo de 2018;

Norma TTN 3.1 Método Comparativo - 3 de mayo de 2005;

Norma TTN 4.1 Método del Costo - 3 de mayo de 2005;

Norma TTN 7.1 Tasación de Expropiación - 3 de mayo de 2005;

Norma TTN 10.3 Requisitos de Informe de Tasación - 2 de febrero de 2015;

Norma TTN 11.4 Valuación de Bienes Muebles - 7 de octubre de 2013;

Norma TTN 18.3 Valuaciones Rurales - 7 de agosto de 2014;

Norma TTN 19.1 Valuaciones de Instalaciones - 7 de agosto de 2014;

Norma TTN 20.1 Valuaciones de Empresas - 7 de agosto de 2014. 
Cabe recordar que la intervención del Tribunal (en la esfera nacional) es de carácter ineludible, cuya ausencia - a todo evento - conduciría a la nulidad de todo lo actuado, sea en sede judicial como administrativa.

Asimismo, la trascendencia de su labor -en aras de desentrañar el valor objetivo de la indemnización - se refleja en el valor que detentan sus dictámenes. En consecuencia, la reiterada jurisprudencia de la Corte ha destacado que los jueces - por regla - deben apartarse de ellos sin razones de grave entidad que lo justifiquen (Fallos 301: 1205 312: 2444; 321: 3701; 323:847; 325: 3292; 326: 2451; 328: 3887 y 329: 5793).

La legislación bonaerense con respecto a bienes inmuebles, regula los extremos a tener en consideración para establecer la indemnización en el artículo 12 de la ley 5708.

Esta norma establece los siguientes parámetros: precio que se abonó en la última transferencia del dominio; valuación asignada para el pago de la contribución directa; diligencias del último avalúo practicado por la Dirección de Catastro; las ofertas fundadas hechas por el expropiante y el expropiado; valor de las propiedades linderas similares en cuanto a situación, superficies y precios abonados en el transcurso de los últimos cinco años; valores registrados en los bancos oficiales de la localidad; valores registrados en las subastas judiciales y particulares por martillero público, en la zona de ubicación del bien; al valor de su productividad durante los últimos cinco años.

En suma, los rubros mencionados se orientan a la determinación del valor real y venal del bien.

Sin perjuicio de lo manifestado, en el ámbito bonaerense (lo cual también se replica a nivel municipal) no se establece cual es el órgano que en sede administrativa efectúa la determinación de la expropiación. La práctica indica que esta labor usualmente es realizada mediante las tasaciones que realiza el Banco de la provincia de Buenos Aires.

\section{Los intereses en la indemnización expropiatoria. Aspectos impositivos. Indexación}

A los fines de garantizar los valores "actuales" de la indemnización, y evitar que la misma devenga irrazonable o confiscatoria, el monto de la indemnización - siempre que aquella no haya sido definida en sede administrativa- deberá ser determinado al momento de dictar la sentencia en el juicio expropiatorio. De no ocurrir ello, difícilmente pueda hablarse de una indemnización equitativa o justa, 
y a su vez — sin duda alguna — se verificaría un enriquecimiento sin causa para el Estado.

Como bien lo señalaba Bielsa (Bielsa y Luqui, 2017), el expropiado que recibe una cantidad nominal y realmente inferior al valor de la cosa expropiada ha sido confiscado, en lo que respecta a la justa indemnización.

La reflexión realizada permite hoy en día interpretar el criterio que se incorpora en los diversos regímenes expropiatorios. En este sentido, guardando relación con el principio de la "previa" indemnización, esta deberá ser establecida —como principio - al momento de la desposesión. Esto se corrobora en el artículo 20 primer párrafo del decreto-ley No 21499 y en los artículos 8, 12 y 35 de la ley provincial No 5708 (SCBA, causa C. 95.063).

Sin embargo, esta regla de origen legal, ha sido atemperada por la jurisprudencia, a los efectos de no vulnerar el principio de indemnización justa que podría verse vulnerado por la pérdida de valor del bien producto - por ejemplo- del flagelo de la inflación. En tal contexto, por ejemplo, la SCBA consideró que, según los casos, la conmensuración de la indemnización al momento de dictar sentencia (causas C. 99.285; C.101.107; C. 100.908).

Como bien se adelanta en el subtítulo, otro recaudo que se toma en consideración para asegurar la integridad de la indemnización es el devengamiento de intereses. Conteste a ello, el período estipulado para fijar la indemnización también adquiere relevancia a los efectos de establecer desde cuando se contabilizan los intereses. Al respecto, la legislación vigente (artículo 20 párrafo segundo decretoley 21499; artículo 8 ley provincial 5708) estipula que los mismos se computarán desde la desposesión, y que, a dichos efectos, aquellos se devengarán únicamente con respecto a las sumas que oportunamente no hayan sido depositadas (es decir, no se tiene en cuenta el monto consignado previo a la desposesión).

Cabe decir que esta regla, en casos de expropiación inversa, sufre una importante variación debido a que los mismos deberán computarse desde el día en el que fue incoada la demanda (Fallos 337: 70).

Con respecto a la tasa de interés aplicable, la ley nacional refiere a que se liquidará a una tasa del $6 \%$ anual. Por vía pretoriana se estipuló que, en estos supuestos, deviene de aplicación la tasa pasiva que abona el Banco de la Nación Argentina (Fallos 317: 1921; 326: 2329; 328: 4507 y 329: 1703).

Sin perjuicio de que el texto normativo incluye la posibilidad de indexar para combatir la depreciación monetaria (artículo 21 segundo párrafo decretoley 21.499; Fallos 268: 112), posteriormente, con la aparición de la ley 23928 (cuyos 
alcances fueron confirmados por la ley 25.561) se ha vedado actualmente esta posibilidad. Asimismo, la jurisprudencia ha convalidado la inaplicabilidad de la depreciación monetaria, con sustento en las normas señaladas, en materia de expropiación (Fallos 334:509; SCBA C. 99.152).

Como manifestación de la integralidad de la indemnización, el monto fijado en sede administrativa o judicial estará exento del pago de impuestos (artículo 21 último párrafo decreto-ley 21499; decreto-ley 21.878; decreto-ley 9313 provincia de Buenos Aires).

Sin embargo, las deudas tributarias del expropiado con el sujeto expropiante pueden ser compensadas, lo cual conduce a que - por añadidura - el Estado pueda detraer las sumas correspondientes que fueran debidas de la indemnización. Corresponde agregar que, el devengamiento de las obligaciones tributarias, finaliza desde al momento de la desposesión (SCBA C.101.097).

\section{Palabras finales}

A lo largo de estas breves líneas hemos intentado abordar el estado de situación de uno de los elementos sustanciales de la expropiación, como lo es la determinación de su indemnización. De tal manera, se ha intentado esquematizar y sistematizar las principales aristas que se desprenden de la indemnización expropiatoria, que representa una temática que a pesar del transcurso del tiempo no pierde relevancia ni validez.

\section{Bibliografía}

Aguilar Valdez, O. (2006). Caducidad, rescisión y rescate de concesiones en materia de infraestructura y servicios públicos. En J. C. Cassagne (dir.), Servicio Público y Policía (p. 187 y ss.). Buenos Aires: El Derecho.

Bidart Campos, G. (2008). Régimen constitucional de la expropiación. La Ley, Doctrinas Esenciales, T. III (p. 785 y ss.). Buenos Aires: La Ley (cita online: AR/ DOC/3518/2008).

Bielsa, R. y Luqui, R. (2017). Derecho Administrativo, T. IV. Buenos Aires: La Ley.

Casas, J. A. y Romero Villanueva, H. J. (2014). Expropiación. Buenos Aires: Astrea.

Cassagne, J. C. (2002). Derecho Administrativo, T. II, Séptima Edición. Buenos Aires: Editorial Lexis Nexis - Abeledo Perrot. 
Forsthoff, E. (1958). Tratado de Derecho Administrativo. Madrid: Instituto de Estudios Políticos.

González, J. V. (1915). La expropiación en el derecho público argentino. Buenos Aires: Librería La Facultad.

González Arzac, R. (1975). El monto de la indemnización expropiatoria y los fines del Estado. Revista de Derecho Administrativo, № 8 (p. 35 y ss.).

Linares, J. F. (1997). Valor objetivo e indemnización en la Ley No 21.499. Revista de Derecho Administrativo, No 15-16 (p. 57).

Maiorano, J. L. (1978). La Expropiación en la Ley 21.499. Buenos Aires: Cooperadora de Derecho y Ciencias Sociales.

Marienhoff, M. S. (1998). Tratado de Derecho Administrativo, T. IV.

Marienhoff, M. S. (1959). Expropiación. Revista Jurisprudencia Argentina, 1959VI (p. 256 y ss.).

Mayer, O. (1982). Derecho Administrativo Alemán. Buenos Aires: Depalma.

Oyhanarte, J. (1957). La expropiación y los servicios públicos. Buenos Aires: Abeledo Perrot.

Perrino, P. E. (2009). La responsabilidad estatal lícita y la indemnización del lucro cesante. Suplemento de Derecho Administrativo, Revista Jurisprudencia Argentina, 2009-IV (p. 2 y ss.)

Villegas, W.(1973). Régimen jurídico de la expropiación. Buenos Aires: Depalma.

Ymaz Videla, E. M. (1999). Protección de Inversiones Extranjeras. Tratados Bilaterales. Sus efectos en las Contrataciones Administrativas. Buenos Aires: La Ley.

\section{Legislación}

Constitución Nacional.

Constitución de la provincia de Buenos Aires.

Decreto-Ley No 21.499. Boletín Oficial de la República Argentina, Buenos Aires, 21/01/1977.

Decreto-Ley No 21.878. Boletín Oficial de la República Argentina, Buenos Aires, 26/09/1978. 
Ley Provincial No 5708. Buenos Aires, 27/01/1987.

Decreto-Ley No 9313. Boletín Oficial de la República Argentina, Buenos Aires, 02/01/1968.

\section{Jurisprudencia}

\section{Corte Suprema de Justicia de la Nación}

Fallos 7: 51.

Fallos 15: 254.

Fallos 32: 358.

Fallos 108: 240.

Fallos 141: 190.

Fallos 159: 351.

Fallos 176: 363.

Fallos 181: 250.

Fallos 195: 187.

Fallos 201: 432.

Fallos 204: 205.

Fallos 204: 626.

Fallos 208: 143.

Fallos 209: 333.

Fallos 211: 1641.

Fallos 212: 2.

Fallos 212: 600.

Fallos 217: 617.

Fallos 217: 804 . 
Fallos 221: 519.

Fallos 224: 706.

Fallos 225: 451.

Fallos 230: 280.

Fallos 237: 38 .

Fallos 238: 335.

Fallos 239: 123.

Fallos 240:219.

Fallos 241: 73.

Fallos 245: 252.

Fallos 254: 441.

Fallos 258: 213.

Fallos 268: 112.

Fallos 270: 210.

Fallos 271: 402.

Fallos 281: 354.

Fallos 281: 360 .

Fallos 296: 55.

Fallos 296: 546.

Fallos 298: 463.

Fallos 298: 550.

Fallos 300: 299.

Fallos 300: 762.

Fallos 301: 1205. 
Fallos 302: 1406.

Fallos 303: 692.

Fallos 303: 1011.

Fallos 305: 407.

Fallos 305: 1897.

Fallos 306: 1409.

Fallos 307: 2006.

Fallos 311: 548.

Fallos 312: 1725.

Fallos 312: 2444.

Fallos 316: 1025.

Fallos 316: 1756.

Fallos 317: 377 .

Fallos 317: 617 .

Fallos 317: 1921.

Fallos 318: 445.

Fallos 319: 2108.

Fallos 321: 3701.

Fallos 323: 847.

Fallos 325:3292.

Fallos 326: 2329

Fallos 326: 2451.

Fallos 328: 3887.

Fallos 328: 4507. 
Fallos 329: 1703.

Fallos 329: 5793.

Fallos 329: 5467.

Fallos 334: 509.

Fallos 337: 70.

Fallos 339: 468.

Suprema Corte de Justicia de la Provincia de Buenos Aires

Acuerdos y Sentencias, Tomo II, página 196.

C. 95.063.

C. 99.152 .

C. 99.285 .

C. 100.908 .

C. 101.097.

C. 101.107.

\section{Dictámenes de la Procuración del Tesoro de la Nación}

Dictámenes 238: 87.

Fecha de recepción: 23-03-2020 Fecha de aceptación: 29-06-2020 